\title{
Lo incondicionado en la pragmática trascendental de K.-O. Apel
}

\author{
The unconditioned in the transcendental pragmatics of \\ K.-O. Apel
}

DAVID LANA TUÑÓN*

Resumen: Ante al auge en la segunda mitad del siglo XX de la crítica a la Modernidad, surgen en el pensamiento continental un nuevo paradigma filosófico que intenta reconstruir aquel proyecto ilustrado de forma renovada. Es la obra de K.-O. Apel y J. Habermas un exponente claro de dicho proyecto. Ambos se proponen hablar de una ética del discurso como respuesta a la necesidad de poner en valor una racionalidad universal. Sin embargo, surgen diferencias de matiz sobre la fundamentación de dicha ética. El problema de "lo incondicionado" no escapa al mismo.

Palabras clave: Incondicionado, Pragmática trascendental, Ética discursiva, Postmetafísica.

\begin{abstract}
Front the rise in the critics of the Modernity in the second half of the 20th century, a new philosofical approach appears, in the continental thinking. This approach tryes to reconstruct the enlighted project in a new way. The works of K.-O. Apel and J. Habermas are clears exponents of this project. Both authors try to propose a discursive ethics as a response to the need of putting in value an universal rationality. However, there are important differences on the foundations on their proposals. The problem about "the unconditioned" is an example of those differences.
\end{abstract}

Keywords: Unconditioned, transcendental pragmatics, Discursive Ethics, postmetaphysics.

Sin duda alguna, son Apel y Habermas los dos máximos exponentes de la llamada ética del discurso. Ambos entran de lleno a dar razones en el debate suscitado acerca de la viabilidad de los presupuestos planteados por la Modernidad, tales como las relaciones entre la ciencia y la ética, así como la posibilidad de una ética de carácter universal y cognitiva. Quedan ya lejos las pretensiones metafísicas o religiosas que daban explicación a la necesidad normativa de todo hombre. Con ello responden a lo que Goméz-Heras denomina la intuición de la historia de la filosofía en el siglo xx, que a la par de lo que supuso la duda

Recibido: 31/05/2019. Aceptado: 29/07/2019.

* Doctor en Filosofía por la Universidad de Valencia (UV). Profesor de Ética y Antropología en la Universidad Católica de Valencia (UCV). Su investigación se centra, principalmente, en el ámbito de la Filosofía Moral y Política. Artículos: "Con-pasión cordial. Del pensamiento atribulado a la razón esperanzada". Ciencia Tomista vol. 139 n 447; "La neuroreligión y los límites del método científico-natural”. Scripta Fulgentina n 43-44. Email: david.lana@icloud.com. 
metódica de Descartes o el giro copernicano de Kant, responden al paradigma hegeliano de «poner la propia época en conceptos».

La situación histórica que les ha tocado vivir ha sido caracterizada por la «crisis de la razón». A dicha crisis responde la obra, tanto de Habermas como de Apel, convencidos de que sin una restauración transformada del Logos ilustrado se derivarían desastrosas consecuencias, tanto en el orden del pensamiento como en el de la praxis efectiva de nuestra cultura occidental. Ambos sienten la necesidad de reconstrucción de la razón, en cuanto razón dialógica, una razón que sea capaz de afrontar la aludida crisis.

Los problemas que aquejan a la humanidad en el mundo contemporáneo son alarmantes. El siglo XX no sólo ha asistido a la hecatombe de las guerras mundiales, sino a diversos procesos de disgregación y tecnificación que se ha extendido a una amplia variedad de aspectos culturales y filosóficos: las crecientes exigencias de racionalidad científica amenazan con invadir el espacio de las ciencias humanas, objetivando al hombre; una tenaz orientación estratégica se apodera de la vida social y política, haciendo fuerte la lucha por el éxito subjetivo y los imperativos deshumanizados que provienen de viejos mecanismos, como el económico y el administrativo; una rivalidad entre puntos de vista culturales o formas de vida, en un mundo globalizado, parece carecer de criterios comunes de convivencia, abriendo así la posibilidad de un relativismo que conduce al escepticismo y la imposición del más fuerte. Una situación tal que urge la necesidad de poner en valor una racionalidad universal, válida para todos y fundada en principios no estratégicos, sino autónomos, que logre frenar la deshumanización acechante y la ruptura de la cohesión interpersonal.

Los proyectos filosóficos que afrontaban dicha situación en el ámbito continental, el hermenéutico y la Teoría Crítica, constituían más bien un obstáculo que una solución a dicha situación; pues ambos, siendo críticos con la situación del presente, han negado, sin embargo la posibilidad de un proyecto ilustrado y universalista al desembocar en una crítica total de la razón. Y una crítica total a la razón es lo que tanto Habermas como Apel ven como sencillamente imposible. Dicha crítica se ve en la obligación de dar razones convincentes universalmente, presuponiendo una racionalidad universal incuestionable. Se requiere reconstruir un Logos discursivo. Toda concepción del mundo, así como toda comprensión acerca de la verdad y de la moral, comportan, no sólo un cuerpo doctrinal determinado, sino, al mismo tiempo, una pretensión de validez universal. Nos situamos ante un presupuesto pragmático de cualquier toma de posición explícita que se proponga como respuesta seria. Pues al pensar con seriedad, el hombre afronta una oferta de comprensión para la cual reclama una adhesión incondicional y universal por parte de cualquier interlocutor. Existe un Logos universal y éste ha de coincidir con los compromisos racionales a los que estamos remitidos por el hecho de que, al ejercer nuestro ser-racional, tengamos por fuerza que pretender validez incondicional. De todo ellos sacamos al menos dos conclusiones: por una parte, el logos universal que buscamos es dialógico; y por otra, la crítica a la razón es en sí misma autocontradictoria.

La filosofía práctica contemporánea está llamada a compartir el mismo reto al que es llamada la filosofía contemporánea, que se ha visto caracterizada por haber sustituido la idea moderna de la subjetividad y su esquema operativo sujeto-objeto por el concepto de la intersubjetividad. Tanto la ontología clásica y premoderna que conformaron el primer paradigma de la construcción de la teoría ética - primer paradigma - como aquel que ha primado 
durante toda la Modernidad sustentado por la subjetividad o ciencia trascendental - segundo paradigma - ha venido a ser reemplazado por el paradigma de la intersubjetividad mediada por el lenguaje, otorgándole racionalidad social a la pretensión de fundamentación de la moral. La incursión del giro lingüístico ha logrado desplazar toda pretensión de fundamentación de la moral bien desde la ontología del ser bien desde la estructura de la conciencia.

\section{Dos proyectos de Ética discursiva: K.-O. Apel y J. Habermas}

K.-O. Apel distingue dos acepciones de la expresión «ética del discurso» $(1998,147-$ 151). Así, la ética del discurso es una teoría de la fundamentación de normas en general, cuya tesis principal dirá que el discurso argumentativo es el procedimiento más adecuado tanto para fundamentar la corrección de normas vigentes cuya validez se cuestiona, como para establecer nuevas normas con la garantía de que pueden considerarse correctas. Dicho «discurso argumentativo» conlleva un modo específico de uso del lenguaje: el intercambio de argumentos. Es este «intercambio de argumentos» el que garantiza la corrección de su resultado, es decir, el acuerdo alcanzado en cada caso por los interesados. Ello nos lleva a encontrarnos con una teoría ética cognitivista y procedimentalista. Es cognitivista en la medida en que afirma la posibilidad de fundamentación de lo normativo de un modo racional siempre desde la intersubjetividad vinculante. Así, los enunciados normativos son susceptibles de fundamentación en la misma medida en que lo son los enunciados descriptivos, si bien el sentido y los criterios de validez son diferentes en los enunciados normativos y en los descriptivos. En Habermas encontramos la siguiente formulación cognitivista de la ética discursiva: «Entiendo la corrección normativa como una pretensión de validez análoga a la verdad. En este sentido hablamos también de una ética cognitivista. Esta tiene que poder responder a la pregunta de cómo es posible fundamentar enunciados normativos» (2000, 15). Pero además, la ética discursiva es una teoría formalista, puesto que sostiene que, con independencia de su contenido concreto, la validez de las normas queda garantizada por las condiciones en las que se lleva a cabo el procedimiento de fundamentación o formulación, que no es otra que el propio discurso argumentativo (Habermas, 2000, 16). Al referirnos tanto al cognitivismo como al formalismo, Habermas relaciona la ética discursiva con la ética kantiana, si bien aquella rechaza el procedimiento kantiano de fundamentación de normas (el imperativo categórico) proponiendo en su lugar un discurso argumentativo, posibilitando así la salvaguarda de los problemas que la ética kantiana suscita ${ }^{1}$.

Apel subraya una segunda acepción de la ética del discurso que le permite definirla en tanto que teoría de la racionalidad: «La idea del discurso argumentativo — de su irrebasabilidad $^{2}$ por parte de cualquier pensamiento con pretensión de validez- debe posibilitar

1 A. Cortina señala tres puntos de distanciamiento: «(1) la ética del discurso es una ética de la responsabilidad y no de la intención, porque tiene en cuenta las consecuencias de la acción; (2) supera la distinción, tantas veces criticada, entre hombre nouménico y fenoménico, entre mundo inteligible y sensible; (3) destruye el "monologismo" desde el momento en que no atribuye a cada individuo la capacidad de comprobar máximas de acción universalizando, sino que recurre al discurso público para lograr el acuerdo acerca de la universalidad de los intereses» (1985a, 110).

2 «La categoría de irrebasabilidad (Nichthintergehbarkeit) tiene una trascendencia en la propuesta filosófica de Apel en su conjunto que resulta difícil encomiar. Aunque resulte anecdótico, para la edición de su 
también la fundamentación última del principio ético que debe guiar ya siempre todos los discursos argumentativos $(\ldots) »^{3}(1998,150)$. Es en esta segunda acepción en la que la ética del discurso aparece definida como teoría de la racionalidad de forma tal que en ella misma, y de forma inevitable, reconocemos siempre ciertos principios éticos o morales ${ }^{4}$, independientemente de la cuestión tratada en cada caso. En toda argumentación o razonamiento se presupone el principio moral del reconocimiento de la igualdad de derechos de todos los participantes en el discurso argumentativo, e idealmente de todos los seres racionales. Pero hemos de entender bien qué quiere decir Apel cuando refiere a este principio ético «presupuesto» en toda argumentación.

No se trata, para Apel, de una premisa implícita o no tematizada, al modo en que, por ejemplo, nuestros enunciados acerca de la naturaleza presuponen la realidad del mundo exterior. Hemos de pensar en la función discursiva de este principio ético comparándolo con las reglas lógicas. Es evidente que existe una diferencia entre el modo en el que permanecen supuestas en nuestras argumentaciones determinadas premisas implícitas y el modo en el que están supuestos los principios lógicos o principio moral fundamental. La validez del principio lógico y del principio moral del reconocimiento de la igualdad de derechos de los otros sujetos racionales no es contingente, ya que no pertenece a los supuestos semánticos de lo que, con Wittgenstein, llamaríamos un «juego de lenguaje»

Transformation der Philosophie se ha elegido como frontispicio un texto, extraído de la última página de la introducción, en el que se alude nada más empezar a la irrebasabilidad del lenguaje ordinario y a su conexión con la comunidad de argumentación. Es un detalle anecdótico, pero a la vez expresivo de que lo irrebasable va a jugar un papel insustituible en el conjunto del pensamiento apeliano. En este momento la categoría se aplica al hecho de la argumentación, que es un hecho máximamente intersubjetivo por irrebasable; es decir, porque los científicos, argumentan para defender sus hipótesis, pero no sólo ellos: a la hora de resolver conflictos los hombres utilizan argumentos, si es que quieren que tal resolución sea racional. [...] La irrebasabilidad de la argumentación consiste, pues, en principio, en la identificación con la conducta racional a la hora de resolver conflictos. Una resolución racional de conflictos es la que se produce por medio de argumentos, y quien no desee proceder argumentativamente, si quiere seguir haciendo gala de un comportamiento racional, debe tener argumentos para no participar en la argumentación efectiva. [...] La argumentación es, pues, irrebasable porque cualquier comportamiento racional debe contar con ella; pero también por el hecho de que la argumentación que se desenvuelve en lenguaje ordinario constituye el techo último posible en la cadena de lenguajes y metalenguajes. El último metalenguaje posible, del que todos los demás son lenguaje-objeto, es el juego de la argumentación "jugado" en el lenguaje ordinario, más allá del cual es imposible ir ya (nichthintergehbar), porque no puede convertirse en lenguaje-objeto de ningún otro metalenguaje, que no tenga, a su vez, que interpretarse nuevamente en lenguaje ordinario» (Cortina, 1985b, 93-94).

3 «Habermas proyecta su pragmática universal como una ciencia encargada de reconstruir las condiciones universales del posible acuerdo; mientras que Apel se propone construir una pragmática trascendental, que detecte aquellas condiciones de posibilidad del acuerdo a las que denominamos trascendentales por irrebasables. La diferencia, pues, radica en el binomio "universal-trascendental", que no representa en modo alguno una alternativa como a primera vista pudiera parecer, porque el mismo Habermas reconoce sin empacho que su fundamentación de la ética comunicativa es trascendental; [...] bástenos decir que ambos autores coinciden en el proyecto de elaborar una pragmática universal no empírica. Si Apel acentúa muy especialmente uno de los eslabones del proceso -el momento de la argumentación- ello se debe a su carácter de racionalmente irrebasable» (Cortina, 1985b, 97).

4 «[R]adicalizaremos nuestra tesis manteniendo que la argumentación racional presupuesta, no sólo en cada ciencia, sino en cada discusión de problemas, presupone la validez de normas éticas universales» (Apel, 1985, I, 377).

Subrayo una precisión terminológica: Apel suele referirse a «principios éticos», a la «norma ética fundamental» [ethische Grundnorm], etc. Habermas, a diferencia de Apel, hablará de «principios morales», ya que sostiene diferencias terminológicas entre las «cuestiones morales» [Moralität] y las «cuestiones éticas» [Sittlichkeit]. 
particular $(1995, \S 24)$. Acudamos a un ejemplo para tener una visión más clara de lo anteriormente expuesto. La realidad del mundo exterior a la conciencia es una premisa siempre supuesta implícitamente en nuestro trato con los objetos físicos, pero se trata de una premisa contingente, como demuestra el hecho de que puede tematizarse y ponerse en cuestión en otro juego de lenguaje como es, el discurso filosófico - pongamos el caso particular de las Meditaciones de Descartes-. Esto no sucede ni con los principios lógicos ni con el principio moral que Apel sitúa entre las condiciones de posibilidad de la argumentación, ya que, tanto los principios lógicos como el principio moral fundamental, pueden ser tematizados en un discurso filosófico, pero no pueden ser rebasados. Ello es así porque cualquier discurso argumentativo, incluido el que pretende ponerlos en cuestión, los presupone siempre. Es ésta la razón por la que Apel atribuye a estos principios un estatuto trascendental en el sentido de Kant. He aquí la gran aportación de Apel a la filosofía contemporánea, el haber incluido una norma moral, un principio de razón práctica, entre las condiciones trascendentales del pensamiento.

Señalo el doble nivel que cabe dentro de la denominada «ética del discurso»: el nivel de la teoría de la fundamentación de normas y el nivel de la denominada por Apel «filosofía primera» - recogido de la antigua concepción aristotélica - entendida como reflexión sobre los principios trascendentales del pensamiento de la racionalidad (Conill, 1983, 493-518). Una vez dicho esto cabe preguntarse, ¿cuál es la relación entre ambas concepciones de la ética del discurso? Si bien podemos argumentar que ambas permanecen relacionadas, del mismo modo, estamos obligados a reconocer que no son idénticas, como no lo son sus relaciones ni sus diferencias. Karl Otto Apel ha tenido el mérito de haber proporcionado la primera formulación de la ética del discurso allá por el año 1967 en un ensayo que llevaba por título: «El a priori de la comunidad de comunicación y el fundamento de la ética», artículo que pretendía dar fundamentación trascendental de los principios morales (Apel, 1985, II, 341-413). Habermas, a diferencia de Apel, formula una ética discursiva, entendida ésta como teoría de la fundamentación de normas, testigo de lo cual está su artículo de 1983 «Ética del discurso. Notas para un programa sobre su fundamentación» (1985, 57-134). Habermas ha querido siempre hacer hincapié en la diferenciación mantenida respecto al modelo filosófico propuesto por Apel, ateniéndose siempre a una interpretación de la ética discursiva en tanto que fundamentación de normas, sin comprometerse con la filosofía trascendental apeliana.

\section{K.-O. Apel y el principio trascendental de la argumentación}

La necesidad de una fundamentación racionalista «postmetafísica» de las normas morales

Dar cuenta de la fundamentación de las normas morales desde una perspectiva racionalista, tal y como lo han intentado Apel y Habermas, resulta sumamente ardua si tenemos en cuenta que ésta ha de ser instalada dentro de lo que Habermas ha llamado «pensamiento postmetafísico», pensamiento que corresponde al aquí y ahora que nos ha tocado vivir. Por «pensamiento postmetafísico» hemos de entender aquella forma de pensamiento que ya no puede apoyarse en certezas o premisas dogmáticas ofrecidas, tradicionalmente, por un 
pensamiento metafísico como podría ser el representado por la religión u otra cosmovisión ${ }^{5}$. En el pensamiento postmetafísico la racionalidad de las proposiciones - tanto en el terreno de las ciencias como en el terreno de la moral o la filosofía - depende enteramente de «los procedimientos conforme a los que se trata de resolver los problemas» (Habermas, 1990, 95). Por ello, toda proposición descriptiva sólo podrá ser considerada aceptable siempre que cumpla los criterios de contrastación que desde las ciencias empíricas queden fijados, mientras que no será aceptable racionalmente ninguna descripción de la realidad que se sustente sobre mitos o doctrinas religiosas. Desde un pensamiento postmetafísico nos queda vedada la posibilidad de acudir a fundamentaciones religiosas o dogmáticas de las normas morales de la misma manera que no podemos apelar al hecho de las tradiciones culturales incuestionables.

Que «no nos está permitido» recurrir a la religión o a la tradición no significa, naturalmente, que no podamos hacerlo. Lo que se quiere decir con ello es que la argumentación que de ahí se haga presente no logrará ser una argumentación lo suficientemente convincente. Dicho planteamiento, si bien no tiene una fuerte consolidación entre aquellos que mantienen unas convicciones propias de alguna manera similares, al modo en que Rawls lo definiría como «doctrina comprenhensiva del bien», sí es manifiesto en la situación de conflicto de diversas posiciones morales, por ejemplo entre culturas diferentes. Es un hecho verificable el que si asumimos de un modo dogmático nuestros propios principios morales en una situación de diálogo, éste se verá imposibilitado, ya que no lograremos entendernos con quienes defienden sus propias convicciones. Y es que el entendimiento le es necesario al ser humano, no podemos prescindir de él. Fundamentar la validez trans-cultural o universal de ciertos principios morales - de igual manera con los principios jurídicos y políticos - es una tarea que se nos impone en un contexto al que hemos llamado globalizado, y al que Apel, ya en los años sesenta, y de forma muy lúcida, refirió bajo la constelación de una «única civilización planetaria» ( 1985, II, 342).

Si bien hemos considerado la necesidad de formular un pensamiento postmetafísico con la consecuente pérdida de credibilidad que aportan las fundamentaciones religiosas o tradicionales, una primera opción filosófica parece la de renunciar a la propia idea de fundamentación racional, lo cual nos llevaría a abandonar la idea misma de fundamentación, puesto que una fundamentación no racional, en el fondo, representa una contradicción en términos. Saliendo de este contrasentido, siempre nos queda acogernos al escepticismo o alguna de las formas posibles de relativismo ético, y afirmar, por ejemplo, que la validez de las normas morales depende siempre del contexto cultural al que el sujeto pertenece, en el caso del relativista, o bien señalar que la validez normativa viene dada por la acción libre ejercida desde la voluntad del individuo. Tanto la solución relativista como la decisionista aparecen de forma extendida en nuestras comunidades culturales ilustradas y «postmetafísicas», es decir, en aquellas comunidades donde las creencias religiosas y las tradiciones culturales han perdido su fuerza de convicción y su capacidad de cohesión. Sin embargo, y a pesar de su proliferación, dichas posiciones presentan una debilidad notable, y es ésta, justamente, su

5 A. Herrera alude al hecho de cambio de paradigma de la siguiente manera: «es el cuestionamiento del pensamiento totalizante, dirigido al Uno y al Todo, por la nueva racionalidad procedimental, la puesta en marcha de la destranscendentalización, el cambio de paradigma de la filosofía de la conciencia a la filosofía del lenguaje y, por último, el hundimiento del primado de la teoría sobre la práctica son las razones expuestas por nuestro autor [J. Habermas] conducentes al abandono de la metafísica» $(2007,81)$. 
inconsistencia. Ambas, el relativismo y el decisionismo, se han de enfrentar con la pretensión de objetividad que pretenden, es decir, con su validez incondicional, con el modo en que emiten sus juicios acerca de cuestiones morales, jurídicas o políticas.

Tugendhat ha señalado muy bien esta inconsistencia (1997, Lección primera). Cuando filosofamos acerca de cuestiones prácticas solemos argumentar bien como escépticos, relativistas o decisionistas, pero cuando juzgamos en tales asuntos lo que hacemos es vincular a nuestros juicos una pretensión de validez que no es relativa a nuestro contexto, sino que, en cierta manera, el juicio queda extrapolado al hecho cultural en el que nos situamos. Otra manera de enfocar la inconsistencia que se da en este tipo de razonamientos argumentará que, si de verdad creyésemos que nuestras convicciones morales dependen de nuestro contexto cultural, no pretenderíamos convencer de su racionalidad en serio a quienes no las comparten con nosotros: si de verdad creyésemos que depende de una decisión existencial radicalmente personal, no discutiríamos acerca de nada de esto, ni siquiera con quienes pertenecen a nuestra propia cultura. Si quisiéramos mantenernos coherentes con nuestro pensamiento, debiéramos guardar silencio, no argumentar, como bien había sugerido Wittgenstein al final de su Tractatus, o Aristóteles en su Metafísica refiriéndose a los relativistas que niegan el principio de contradicción, semejándolos a una planta (1990, 1006a 16, 1008b 10).

La cuestión suscitada aparece abierta. Resulta difícil resolver la incoherencia entre la pretensión de objetividad del lenguaje moral común y el escepticismo de la reflexión filosófica. Nada impide, en un primer momento, mantener hasta el final una actitud escéptica frente a dicha pretensión del lenguaje moral. Tanto Apel como Habermas han argumentado que no es posible mantener como participantes en la comunicación cotidiana, es decir, no en el nivel de la reflexión filosófica, sino en el de interacción comunicativa, un escepticismo ético coherente sin caer en la neurosis o incluso en el suicidio (Apel, 1985b, 341-413; Habermas, 1985). La pretensión de validez objetiva que vinculamos a nuestros enunciados normativos sugiere un modo alternativo de racionalización que consiga reconstruir y fundamentar a nivel filosófico la pretensión de objetividad del lenguaje común, sin la necesidad de recurrir a criterios de autoridad dados por discursos religiosos o tradiciones culturales. Ésta sería, justamente, la vía de fundamentación racionalista y postmetafísica de las normas morales, fundamentación que han querido explorar tanto Apel como Habermas.

La pretensión de fundamentación racionalista y postmetafísica de las normas morales no deja de enfrentarse también a la dificultad que suscita el mismo concepto de «razón»o «racionalidad». La cultura que se adscribe a la pretensión postmetafísica se viene caracterizando también por la creciente monopolización del concepto de racionalidad por parte de las ciencias empíricas, que siguen, en mayor o menor medida, el modelo monológico-deductivo de las ciencias de la naturaleza. Ya Adorno y Horkheimer, en su obra Dialéctica de la Ilustración definieron al hombre, bajo el modelo de razón surgido del proceso ilustrado, como «antropomorfismo», reduccionismo del concepto de hombre imbuido por una ilustración claramente científica y positivista $(1998,119)$. La pretensión de dar respuestas racionales a problemas importantes para la vida y la convivencia de los hombres, como son, entre otros, los problemas morales y políticos, queda relegada al pensamiento mítico, a las ingenuas formas de la conciencia precientífica. Es por ello, que desde una cultura postmetafísica la tarea de proporcionar una fundamentación racional de las normas morales no exige sólo rechazar el decisionismo o el relativismo, sino también el cientificismo, es decir, la hegemonía cultural 
de las ciencias empíricas (Apel, 1985, II, 344ss). Se hace necesario construir un concepto de racionalidad que no se agote en la misma racionalidad de las ciencias, o lo que es lo mismo, hacer plausible que las explicaciones nomológicas-deductivas de fenómenos empíricos no sean los únicos discursos o «juegos de lenguaje» que cabe calificar de racionales ${ }^{6}$.

En su Transformación de la Filosofía, Apel logra resumir en tres proposiciones las premisas básicas que comportan el monopolio científico de la racionalidad, con el consecuente afianzamiento del irracionalismo en las cuestiones prácticas. Dichas premisas son:

1. A partir de hechos no pueden derivarse normas (o bien: a partir de enunciados descriptivos no pueden deducirse enunciados prescriptivos ni, por consiguiente, «juicios de valor»). [...]

2. La ciencia, puesto que proporciona conocimientos con contenido, versa sobre hechos; de ahí que sea imposible fundamentar científicamente la ética normativa.

3. Sólo la ciencia proporciona un saber objetivo; la objetividad se identifica con la validez intersubjetiva; por tanto, una fundamentación intersubjetivamente válida de la ética normativa es absolutamente imposible (1985, II, 359).

Apel nos está diciendo que el saber científico, en cuanto que intersubjetivo, es un saber de hechos, o lo que es lo mismo, la ciencia no puede pronunciarse sobre cuestiones normativas, no sin incurrir en falacia naturalista, es decir, en inferir normas a partir de enunciados descriptivos. Apel intenta escapar de la aporía que suponen estas tres premisas aceptando las dos primeras y negando la tercera. A diferencia de lo que resultará en Habermas, Apel no pretende mostrar simplemente las condiciones en que puede considerarse fundamentado un enunciado normativo. Tratará de mostrar que «la "objetividad" de la propia ciencia (...) presupone la validez intersubjetiva de normas morales». Es decir, tratará de mostrar mediante la reflexión trascendental en sentido próximo a Kant, que entre las condiciones de posibilidad de la argumentación científica en general se incluyen normas morales, o al menos, encontrar un principio que pueda servir como fundamento a todos los demás.

\section{Argumentación trascendental y «contradicción performativa»}

Es Kant quien, por vez primera, aplica de forma sistemática un tipo de argumentación consistente en partir de una proposición que considera cierta o probada para remontarse a continuación a sus «condiciones de posibilidad». En la medida en la que consideramos la verdad de la proposición como punto de partida y ésta depende de la verdad en otras proposiciones que expresan su condición de posibilidad, el argumento trascendental permite demostrar la verdad de las últimas. En la Crítica de la razón pura, Kant, aplica este tipo de razonamientos a la demostración de la idealidad del espacio - como condición de posibilidad de la geometría - y la objetividad de las categorías - como condiciones de posibilidad de la experiencia en general-, o también en la refutación del idealismo.

6 «La ciencia ha perdido ya aquella primacía en la búsqueda racional y progresiva de la verdad que, en la Edad Moderna, la había convertido en una alternativa postmetafísica a la metafísica. Cuando menos, es evidente lo siguiente: o bien la ciencia afirma su pretensión de racionalidad y de verdad, lo cual no parece poder hacerse con independencia del discurso argumentativo de la filosofía e incluso de las hipótesis globales metafísicamente inspiradas; o bien, por el contrario, pierde -junto con la metafísica y la filosofía- su pretensión de un conocimiento progresivo de la verdad que rebase la persuasión del conocimiento cotidiano» (Apel, 2002, 28). 
Apel toma de Kant la idea de que el pensamiento o la argumentación están sujetos a un conjunto de reglas o principios universales y necesarios, es decir, trascendentales ${ }^{7}$. Sin embargo, el procedimiento para demostrar la validez de estos principios no coincide exactamente con las argumentaciones de Kant. De ahí la necesidad de explicitar en qué consiste la fundamentación trascendental a partir del principio de no contradicción en la teoría de Aristóteles contra los sofistas. Frente a Kant, la argumentación de Aristóteles tiene la ventaja de mantenerse en un terreno lingüístico o lógico, lo cual no sólo evita el lastre de los supuestos del idealismo kantiano, sino que además aproxima estos argumentos al enfoque estrictamente de la filosofía de Apel.

En Aristóteles encontramos formulado el principio de no contradicción en unos términos cercanos a la concepción kantiana o apeliana de los principios trascendentales. Se trata de un principio que «no es hipotético» y que «uno ha de poseer ya necesariamente» cuando se propone conocer cualquier otra cosa (Aristóteles, 1990, 1005b 10-15). En el lenguaje utilizado por Kant diríamos que se trata de un principio universal y necesario. Según Aristóteles este principio no puede definirse deductivamente a partir de otros principios más generales, debido precisamente a su carácter universal y necesario, o al hecho de que se encuentra ya siempre presupuesto en cualquier razonamiento. Sin embargo, es posible probar indirectamente su validez recurriendo a una «demostración refutativa» (Aristóteles, 1990, 1006 12). Aristóteles, en su pretensión de disputar con los sofistas, que niegan el principio de no contradicción, argumentará que, lo quieran o no lo quieran, al negar este principio lo están presuponiendo ya siempre en sus argumentaciones, dado que de lo contrario no estarían afirmando nada, ni siquiera la tesis de que dicho principio no es válido. Con ello Aristóteles lo que nos está queriendo argumentar es que el sofista que intenta «destruir el razonamiento sigue manteniendo el razonamiento» (1006a 26). Si admitimos el razonamiento de Aristóteles como válido estamos afirmando la validez de dicho principio, y su validez a priori, es decir, universal y necesaria, en terminología kantiana. Apel diría que nos situamos ante un principio «irrebasable» [Nichthintergehbar] de la argumentación, o lo que es lo mismo, no nos podemos situar detrás de él [hintergehen], bien sea para fundamentarlo deductivamente a partir de algún otro principio más general, bien para negar su validez. La prueba del estatuto trascendental o «irrebasable» del principio de contradicción es precisamente la contradicción en que incurre quien, como el sofista al que se enfrenta Aristóteles, pretende negarlo con argumentos.

Apel denomina a esta contradicción «autocontradicción performativa». Esta no ha de identificarse en el uso de términos contradictorios en las argumentaciones, ya que, desde el punto de vista semántico, no encontramos contradicción en una proposición tal como «afirmo que el principio de contradicción carece de validez». En dicha proposición encontramos una contradicción, en la medida en la que el principio de contradicción es condición

7 En la filosofía de Kant, el adjetivo «trascendental» se aplica en primer lugar al conocimiento filosófico. Son trascendentales las proposiciones filosóficas que afirman que un concepto o unos principios son a priori, es decir, no proceden de la experiencia y al mismo tiempo condicionan la experiencia universal y necesaria (1997, B 25). Pero ya el propio Kant modifica el sentido de este término aplicándolo también a los propios conceptos o principios apriorísticos: «trascendental» no es sólo la proposición filosófica que declara que, por ejemplo, el principio de causalidad no es válido a priori, sino que el propio principio de causalidad puede considerarse, a su vez, trascendental. Sobre este desplazamiento, que se hace predominante en la recepción de Kant por parte de la filosofía analítica. (Habermas, 1994, 320-322). 
necesaria de la atribución de un sentido unívoco a los términos del lenguaje, siendo condición de toda argumentación. La «autocontradicción performativa» se da entre el contenido proposicional y el componente ilocucionario de los actos de habla, de lo que infieren, tanto Apel como Habermas, que dicha contradicción se plantea en el uso pragmático del lenguaje, y no en su consideración semántica ${ }^{8}$.

\section{Un incondicionado trascendental en toda argumentación: la «norma ética fundamental»}

Hasta aquí hemos visto cómo la reflexión trascendental acerca de las condiciones de posibilidad de la argumentación puede ser resultado de varios principios diferentes. Por una parte, desde la Metafísica de Aristóteles, nos encontramos una fundamentación del principio de no contradicción que puede interpretarse como un argumento trascendental en el sentido de Apel. Por otra parte, en Kant, en su Crítica de la razón pura (A 148-153), observamos cómo nos encontramos con un conjunto más amplio de principios trascendentales que utiliza un método que no coincide con el utilizado por Aristóteles contra los sofistas, pero que tampoco coincide con la consideración de las argumentaciones trascendentales de Apel9 ${ }^{9}$. Éste, menciona un conjunto de principios que incluye la proposición de la propia existencia del sujeto que argumenta, el principio de falibilidad de toda proposición empírica de Popper - principio que es considerado como no falible por el propio Apel- y el reconocimiento de las cuatro pretensiones de validez de los actos de habla que distingue Habermas. Es necesario que nos centremos en este último punto: el reconocimiento de las pretensiones de validez del habla inserto en la propia definición de discurso.

Apel nos dirá que dichas pretensiones de validez son constitutivas, es decir, están insertas en toda argumentación «exactamente en el mismo sentido» en el que lo está el cógito cartesiano $(1998,134)$. De la misma manera que nos resulta imposible negar la existencia del yo en la medida que toda argumentación tiene un sujeto que la realiza nos es imposible negar que con todo acto discursivo entablamos una pretensión de inteligibilidad, de verdad, de corrección normativa y de veracidad. De no ser así, incurriríamos en lo que hemos denominado «autocontradicción performativa». Apel lo intentará exponer con los siguientes ejemplos:

«Yo no existo»

«Tú no existes»

«No tengo ninguna pretensión de comprensibilidad»

«No tengo (como filósofo) ninguna pretensión de verdad» (R. Rorty)

«Defiendo el disenso como objetivo del discurso» (tesis posmodernista)

«Toda argumentación es usar la fuerza» (tesis posmodernista). (1998, 124) ${ }^{10}$

8 A modo de ejemplo, véase Apel y su explicación de la contradicción performativa en la que incurre el pensamiento deconstructivista de la metafísica logocéntrica (Derrida). (2002, 33ss.).

9 Entre los principios trascendentales que Kant distingue no se encuentra el principio de no contradicción, pues para Kant éste es un principio analítico que pertenece a la «lógica formal» (y no a la «lógica trascendental») y que, en esta medida, no requiere una «deducción trascendental».

10 Frente a estos ejemplos que ofrece K.-O. Apel, L. Sáez propone una sistematización de los supuestos trascendentales de la comunión que incluye: a) la comunidad real de comunicación; b) la comunidad ideal de comunicación; c) presupuestos de existencia referidos al yo, al mundo externo y a otros sujetos (1995, 157ss). 
Si pretendemos demostrar la contradicción performativa en la que incurren dichas proposiciones tendríamos que explicitar su sentido ilocucionario y yuxtaponerlo a su contenido proposicional. Con ello, respecto al cuarto ejemplo resultaría lo siguiente: «Afirmo (con pretensión de verdad) que ninguna de mis afirmaciones (tampoco ésta) tiene una pretensión de verdad». Del quinto ejemplo resultaría la proposición: «Afirmo, con la pretensión de convencer racionalmente a mi interlocutor, que el empleo del lenguaje no tiene (ni puede tener) la pretensión de convencer y llegar a un acuerdo con un interlocutor, sino simplemente la pretensión de perpetuar y ahondar el disenso entre hablante y oyente». En el ejemplo donde Apel hace referencia a Richard Rorty, hemos de decir que la contradicción performativa se encuentra en la negación de la pretensión de verdad que todo acto del habla lleva consigo. En el ejemplo siguiente lo negado ya no es la pretensión de verdad implícita en la propia proposición, sino que lo que niega es la posibilidad de entendimiento como hecho constitutivo de la comunicación ${ }^{11}$.

La cuestión que se suscita ahora es en qué medida puede admitirse que, entre las condiciones trascendentales de la argumentación, encontramos no sólo principios lógicos o pragmáticos, sino como entiende Apel, una norma moral. Apel y Habermas no extraen la misma conclusión de aquella tesis que sostienen que los fines ilocucionarios de los actos del habla solo pueden alcanzarse cooperativamente, es decir, mediante el acuerdo racional entre hablante y oyente. Si recordamos a Wittgenstein en sus Investigaciones filosóficas, extiende esta idea del lenguaje a todo uso del mismo, incluido el empleo de términos simples (tales como «mesa», «casa», etc.) (Wittgenstein, 1998, § 1999). Wittgenstein nos dirá que no es posible que un único sujeto emplee un término o una proposición correctamente dado que un solo sujeto nunca podrá estar seguro de su empleo correcto. Dicha tesis se sigue de la «teoría del significado como uso» de Wittgenstein desarrollada precisamente en su obra Investigaciones filosóficas. En la filosofía previa a las Investigaciones se nos decía que el significado de las expresiones lingüísticas es idéntico a su referente, es decir, al objeto del mundo al que las expresiones se refieren ${ }^{12}$. Wittgenstein vino a dar un giro importante a la teoría del lenguaje de suerte tal que el significado de las expresiones lingüísticas no son ya su referente intramundano, sino las reglas de uso en un juego del lenguaje, de lo cual se sigue que tanto el aprendizaje como el empleo correcto de un lenguaje presuponen una comunidad de (al menos dos) hablantes. La corrección del seguimiento de una regla por parte de un hablante sólo puede constatarla otro hablante que la comparta (Habermas, 1990, 113-116). Esta idea nos lleva a otra tesis de Wittgenstein

11 Hemos de recordar que también es posible un uso del lenguaje no orientado al entendimiento (sino, por ejemplo, a provocar determinadas reacciones en el oyente). El uso del lenguaje perlocucionario del lenguaje depende «parasitariamente» de su uso ilocucionario. Por otra parte, en escritos más recientes, Habermas parece abandonar parcialmente la idea de que el acuerdo es la finalidad de la comunicación, y caracteriza con más precisión las formas de interacción basadas en una comprensión de las manifestaciones lingüísticas de un hablante que, sin embargo, no implica el reconocimiento de todas las pretensiones de validez entabladas por él. (Habermas, 2002, 99-131).

12 Según Wittgenstein, la descripción del aprendizaje de una lengua que ofrece san Agustín en sus Confesiones -y que Wittgenstein cita en el parágrafo 1 de su obra- sólo es correcta si se aplica al aprendizaje de una nueva lengua por parte de quien ya dispone de su propia lengua materna, pero no sirve para describir el aprendizaje de ésta. Aprender una lengua es aprender las reglas de uso de sus expresiones, y no la correspondencia entre los términos y sus referentes intramundanos $(1998, \S 1)$. 
que hace referencia a la imposibilidad de los lenguajes privados. La teoría del significado, como uso, excluye como principio la posibilidad de que por sí solo se genere un lenguaje. Un lenguaje que sólo conociera un sujeto que lo usase significaría más bien un lenguaje cifrado que un lenguaje privado. La traducción de dicho lenguaje conocido sólo por un único hablante requeriría de un lenguaje ya existente, regulado ahora sí por reglas públicamente conocidas entre una comunidad de hablantes ${ }^{13}$.

Apel, tomando la tesis de Wittgenstein acerca del carácter constitutivamente intersubjetivo de las reglas de uso de toda expresión lingüística, extrae de ellas consecuencias éticas. El pensamiento es siempre, según Apel, incluso cuando se lleva a cabo en solitario, una forma de comunicación. De la misma forma que toda intersubjetividad es condición de posibilidad del uso correcto de una expresión lingüística, también la corrección lógica de una argumentación puede ser contrastada por una comunidad de comunicación, bien sea real o virtual, es decir, anticipada por un sujeto que discurre en solitario. La conclusión lógica que se sigue dirá que el pensamiento es siempre, incluso cuando se lleve en solitario, una forma de comunicación. Ahora bien, en la medida en que la comunicación es a su vez una forma de interacción entre sujetos, está sometida a por lo menos una norma moral. En el hecho de reconocer a los otros sujetos racionales como una comunidad de argumentación ya siempre presupuesta en nuestras operaciones intelectuales, incluso aquellas que se realizan en solitario, implica reconocer, al mismo tiempo, los derechos de dichos participantes en la argumentación. Apel reconoce dicha norma moral como exigencia formulada de la siguiente manera: «en la comunidad de argumentación se presupone que todos los miembros se reconocen recíprocamente como interlocutores con los mismos derechos» (1985, II, 380). Dicha norma moral está inscrita en las condiciones trascendentales de la argumentación. Dicho razonamiento presupone no sólo una comunidad de comunicación sino además, y de forma simultánea, una comunidad moral. Apel incorpora el concepto de «persona», en sentido hegeliano, en las veces de «participantes en la discusión», de suerte tal que la norma ética fundamental queda formulada de la siguiente manera:

[T]odos los seres capaces de comunicación lingüística deben ser reconocidos como personas puesto que en todas sus acciones y expresiones son interlocutores virtuales, y la justificación ilimitada del pensamiento no puede renunciar a ningún interlocutor y a ninguna de sus aportaciones virtuales a la discusión.

Con dicha formulación hemos entrado de lleno en el lenguaje propio del discurso ético.

Dichas consideraciones hacen de la teoría de Apel una argumentación cargada de mediaciones que a juicio de Habermas no queda exenta de complejidad y de inverosimilitud ${ }^{14}$. Para poder demostrar el carácter trascendental de dicha norma tendríamos que acudir a demostrar que su negación incurriría en contradicción performativa, y Apel la cree haber encontrado formulándola de la siguiente manera:

13 Es por esto que el «giro lingüístico» suscitado en el pensamiento del siglo Xx ha de interpretarse más bien como un «giro pragmático».

14 «El proyecto [apeliano] de Letzbegründung [fundamentación última] está colgado de tantas pinzas que la estrategia de encontrar un único argumento definitivo no tiene ninguna perspectiva de éxito» (Habermas, 2003, 41). 
El esquema de la autocontradicción performativa [...] obtiene su sentido sólo en la fractura [...] entre lo que yo afirmo y lo que implica performativamente mi afirmación [...]: por ejemplo, en la fractura entre la proposición «yo no necesito reconocer, en principio, la igualdad de derechos de todos los participantes imaginables en la argumentación» y el acto de afirmación por el que precisamente esa tesis se pone en discusión como capaz de ser consensuada universalmente (1998, 136).

Cuando se habla del sentido ilocucionario de todo acto de habla (no sólo de los actos de habla regulativos) se refiere a la pretensión de convencer racionalmente de su validez a todos los miembros de la comunidad de seres racionales, lo cual lleva consigo el reconocimiento de sus derechos como participantes en la argumentación. Este segundo aspecto, el reconocimiento de todos los derechos de los participantes en la argumentación, puede interpretarse según lo hace Apel como el reconocimiento de una norma moral. Lo que ha conseguido Apel es introducir una norma moral en la misma estructura de la racionalidad. En esto consiste la «ética del discurso» en la acepción apelina de este término. Con ello, tanto el discurso, la argumentación, la lógica o la ciencia misma no se someten sólo a reglas lógicas internas, a las que después pudiera superponerse imperativos normativos externos (como son los que, por ejemplo, se discuten en los debates acerca de los fines de la investigación o acerca de la responsabilidad social de la ciencia). Apel ha llegado a un nivel mucho más profundo, mucho más fundamental: toda argumentación está sometida al principio moral del reconocimiento de otros sujetos como sujetos iguales. Y lo que es aún más interesante, para Apel, toda argumentación está sometida a esta norma moral en la misma medida en que está sometida a las constricciones que imponen los principios lógicos - principio de contradicción - o pragmáticos - pretensiones de validez-.

Habermas, ve con recelo las dos tesis fundamentales de la ética del discurso de Apel, ya que la norma ética fundamental no es un principio trascendental y tampoco puede ser un principio moral. Habermas, en su versión de la ética discursiva, abandona toda pretensión trascendental al modo de Apel a favor de una teoría de la fundamentación de normas, reinterpretando el principio de Apel como una regla de la argumentación práctica, análoga al principio de inducción que se emplea ordinariamente en las argumentaciones teóricas, como lo son las científicas.

Apel ha mostrado siempre su adhesión al proyecto de Habermas, aportando, al mismo tiempo, una alternativa que ha quedado expresada en continuas tomas de posición «con Habermas contra Habermas». La diatriba entre ambos, no es resultado tanto del análisis sino en cuanto al papel que ocupa la filosofía y el método que le es propio. Habermas ha intentado desvincularse de un trascendentalismo fuerte, que le ha derivado a una pragmática universal que se construye desde el método reconstructivo, que renuncia, en primer lugar, a una estricta separación entre lo apriórico y lo a posteriori o empírico, y por lo que, en segundo lugar, atribuía a dicha reconstrucción un carácter hipotético y falible incompatible con lo que él considera una posición fundamentalista. Apel se opone de forma contundente a estos dos presupuestos, dado que la reflexión filosófica puede tematizar los presupuestos de la razón como condiciones que, si bien están insertas en el tejido de la acción comunicativa del mundo de la vida, son en todo momento elementos a priori que no deben ser confundidos con sus plasmaciones empíricas. La filosofía, en cuanto reflexión dialógica, le 
está permitido alcanzar tal grado de certeza que, a juicio de Apel, está autorizada para hablar de una fundamentación última. El discurso no puede entenderse sólo como una instancia inmanente a cualquier institución del obrar del ser humano, sino que, al mismo tiempo, éste debe ser trascendental respecto de ellas.

Habermas defiende un trascendentalismo débil, según el cual «llamamos "trascendental" a la estructura conceptual que se repite en todas las experiencias coherentes, mientras no quede refutada la afirmación de su necesidad y universalidad» $(1994,321)$. A este reto responde el propio Apel que, aludiendo a la misma teoría reconstructiva, recurre a la racionalidad discursiva para justificar su análisis y que, por tanto, presupone criterios pragmático-trascendentales al acercarse a la historia. Ahora bien, ¿ es posible semejante fundamentación? La respuesta es dada por Apel en el desarrollo de la discusión con el falibilismo pancrítico defendido por el racionalismo crítico de Popper y H. Albert (1985, II, 385-402; 1998, 128-145).

\section{El concepto hermenéutico-trascendental del lenguaje}

La pragmática trascendental, como reflexión filosófica sobre las condiciones de posibilidad del acto de argumentar, converge con la perspectiva habermasina en lo que respecta a los universales de la razón dialógica. De aquí se sigue, en primer lugar, que quien argumenta presupone ya su pertenencia a una comunidad real de comunicación sustentada en un acuerdo mínimo, cuya estructura es la de la recíproca aceptación de pretensiones de validez. En un segundo lugar, que quien acepta el compromiso de justificar con razones sus pretensiones y, acepta, al mismo tiempo, que sólo puede llevarse a cabo mediante la victoria de los mejores argumentos, está orientándose hacia el entendimiento. En un último paso, la comunidad ideal de comunión queda anticipadada. Ésta resulta equivalente a la «situación idea de habla» que propone Habermas. El reconocimiento de tales presupuestos puede ser aprehendido mediante una autorreflexión in actu del argumentante y su a prioridad se confirma, además, en que no pueden ser negados sin autocontradicción performativa.

En el proyecto apeliano de una filosofía transformada en filosofía dialógica le lleva a transformar semióticamente la filosofía trascendental que hereda (Sáez, 1995). Dicha transformación es el paradigma definitivo en el que ha de culminar el esfuerzo histórico por elaborar una filosofía primera. Tras el paradigma pre-moderno, que fundaba los principios del ser en una metafísica realista y pre-crítica, el giro copernicano kantiano instauró un nuevo espacio en el que la comprensión del ser quedaba vinculada a las condiciones formales del conocimiento, siendo lo real comprendido, así, como ser-para el sujeto. Pero este segundo paradigma, sin embargo, adolece de las deficiencias características de la filosofía de la conciencia o del sujeto, pues no se ha percatado todavía de que la conciencia está inserta en el tejido de las relaciones interpersonales. Dichas limitaciones pueden ser rebasadas desde el giro lingǘrtico que surge en el silgo xx, ya que el lenguaje se entiende como instancia comunicativa, allende la subjetividad autónoma de los sujetos particulares. La pragmática trascendental desplaza el análisis kantiano de las condiciones universales de la racionalidad hacia la comunicación lingüística. Ahora bien, el lenguaje es un fenómeno inscrito en la praxis del mundo de la vida, y es por ello también el medio en el que se despliegan las interpretaciones del mundo desde la tradición y las formas de vida. Por eso, según Apel, la pragmática trascendental no puede ser separada de una hermenéutica trascendental, capaz 
de dar cuenta de las condiciones de lo que llamaba Heidegger «comprensión del sentido». Ambas permanecen entretejidas en el marco general de una semiótica trascendental, genuina destinataria de la transformación del trascendentalismo.

Ambas perspectivas, complicadas en la semiótica, están contempladas en el concepto hermenéutico-trascendental del lenguaje, haciendo de ésta una de las aportaciones de Apel más interesantes al escenario filosófico. Así, parte de esta concepción del acuerdo, en cuanto que presupuesto trascendental, es así mismo un proceso que se desarrolla lingüísticamente y que, por tanto, involucra aceptar el carácter trascendental de aquella dimensión del lenguaje en la que toma asiento (Apel, 1985, II, 315-341). Dicha dimensión es, al mismo tiempo, pragmática y hermenéutica, tratándose de una dimensión pragmática en la medida en que el entendimiento arraiga en la interacción mediante actos de habla que vehiculan pretensiones de validez. Ahora bien, se trata también de una dimensión hermenéutica, dado que lo real se hace presente al hombre siempre en cuanto algo interpretado ${ }^{15}$. Y este «en cuanto»o «como» de la presentación del ente es a lo que, de Husserl a Gadamer, recibe el nombre de «sentido». Pues bien, la comprensión del sentido de lo real es precisamente lo que Apel, en correspondencia a dicha tradición, vincula con la dimensión hermenéutica del lenguaje. Con ello, el acuerdo que resulta presupuesto en la comunicación adquiere una dimensión ontológica fundamental «porque ésta no puede reducirse a la comunicación lingüística de informaciones sobre estados de cosas pensados, sino que, en tanto que "acuerdos sobre el sentido" es, a la vez, acuerdo sobre el sentido de las palabras y sobre el sentido del ser de las cosas, mediadas por el significado de las palabras» (Apel, 1985, II, 321). Para Habermas, la incidencia hermenéutico-ontológica de la acción comunicativa, no estando del todo ausente, queda diluida en una orientación más sociológica.

\section{Bibliografía}

ADORNO Th.-W. - Horkheimer, M. (1998), Dialéctica de la Ilustración. Madrid: Trotta. APEL, K.-O. (1985), La transformación de la filosofía, 2 vols. Madrid: Taurus.

APEL, K.-O. (1998), Teoría de la verdad y ética del discurso. Barcelona: Paidós.

APEL, K.-O. (2002), Semiótica trascendental y filosofía primera. Madrid: Síntesis.

ARISTÓTELES, (1990), Metafísica (Edición Trilingüe). Madrid: Gredos.

CORTINA, A. (1985a), La hermenéutica crítica de Apel y Habermas. ¿Ciencia reconstructiva o hermenéutica trascendental?, in Estudios Filosóficos, pp. 83-114.

CORTINA, A. (1985b). Razón comunicativa y responsabilidad solidaria. Ética y política en K.-O. Apel. Salamanca: Sígueme.

HABERMAS, J. (1985), Conciencia moral y acción comunicativa. Barcelona: Península.

HABERMAS, J. (1990), Pensamiento postmetafísico. Madrid: Taurus.

HABERMAS, J. (1994), Teoría de la acción comunicativa: complementos y estudios previos. Madrid: Cátedra.

15 La hermenéutica que ha devenido de Heidegger y Gadamer ha insistido en que el encuentro primordial del hombre con los objetos del mundo es interpretativo, con lo cual la aprehensión pura de un hecho no es más que una falacia que el positivismo ha difundida injustificadamente. Los entes del mundo no son primero representados asépticamente en la conciencia y ulteriormente interpretados. Estos son accesibles sólo desde el horizonte que proporciona una determinada comprensión interpretativa de su ser. 
HABERMAS, J. (2000), Aclaraciones a la ética del discurso. Madrid: Trotta.

HABERMAS, J. (2002), Verdad y justificación. Madrid: Trotta.

HABERMAS J. (2003), La ética del discurso y la cuestión de la verdad. Barcelona: Paidós. HERRERA, A. (2007), De animales y hombres. Oviedo: Biblioteca Nueva.

KANT. I. (1997), Crítica de la Razón Pura. Madrid: Alfaguara.

SÁEZ, L. (1995), La reilustración filosófica de K.-O. Apel. Granada: Universidad de Granada.

TUGENDHAT, E. (1997), Lecciones de ética. Barcelona: Gedisa.

WITTGENSTEIN, L. (1995), Sobre la certeza. Barcelona: Gedisa.

WITTGENSTEIN, L. (1998), Investigaciones filosóficas. Barcelona: Atalaya. 